\title{
Tuning Hot Carrier Cooling Dynamics by Dielectric Confinement in Two-Dimensional Hybrid Perovskite Crystals
}

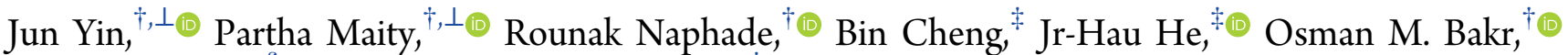
Jean-Luc Brédas, ${ }^{\S}$ and Omar F. Mohammed ${ }^{*}{ }^{\dagger}$.

\begin{abstract}
${ }^{\dagger}$ Division of Physical Science and Engineering, King Abdullah University of Science and Technology, Thuwal 23955-6900, Kingdom of Saudi Arabia

ॠComputer, Electrical, and Mathematical Sciences and Engineering Division, King Abdullah University of Science and Technology, Thuwal 23955-6900, Kingdom of Saudi Arabia

${ }^{\S}$ School of Chemistry and Biochemistry, Center for Organic Photonics and Electronics (COPE), Georgia Institute of Technology, Atlanta, Georgia 30332-0400, United States
\end{abstract}

\section{Supporting Information}

ABSTRACT: Hot carrier (HC) cooling is a critical photophysical process that significantly influences the optoelectronic performance of hybrid perovskite-based devices. The hot carrier extraction at the device interface is very challenging because of its ultrashort lifetime. Here, ultrafast transient reflectance spectroscopy measurements and time-domain $a b$ initio calculations show how the dielectric constant of the organic spacers can control and slow the HC cooling dynamics in single-crystal 2D Ruddlesden-Popper hybrid perovskites. We find that $(\mathrm{EA})_{2} \mathrm{PbI}_{4}\left(\mathrm{EA}=\mathrm{HOC}_{2} \mathrm{H}_{4} \mathrm{NH}_{3}^{+}\right)$that correspond to a
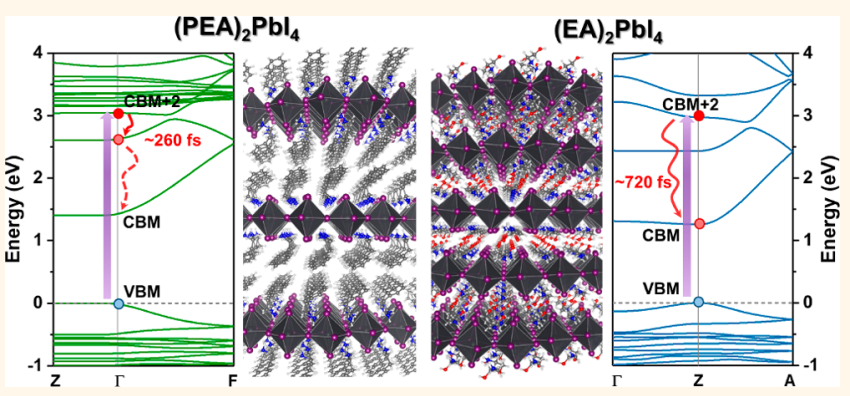
high dielectric constant organic spacer has a longer $\mathrm{HC}$ cooling time compared to that of $(\mathrm{AP})_{2} \mathrm{PbI}_{4}(\mathrm{AP}=$ $\left.\mathrm{HOC}_{3} \mathrm{H}_{6} \mathrm{NH}_{3}^{+}\right)$and $(\mathrm{PEA})_{2} \mathrm{PbI}_{4}\left(\mathrm{PEA}=\mathrm{C}_{6} \mathrm{H}_{5} \mathrm{C}_{2} \mathrm{H}_{4} \mathrm{NH}_{3}^{+}\right)$. The slow $\mathrm{HC}$ relaxation process in the former case can be ascribed to a stronger screening of the Coulomb interactions, a small nonradiative internal conversion within the conduction bands, as well as a weak electron-phonon coupling. Our findings provide a strategy to prolong the hot carrier cooling time in low-dimensional hybrid perovskite materials by using organic spacers with reduced dielectric confinement.

KEYWORDS: 2D hybrid perovskites, dielectric confinement, hot carrier cooling, nonadiabatic molecular dynamics, electron-phonon coupling

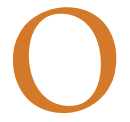

rganic-inorganic hybrid perovskites have been intensively explored as next-generation semiconducting materials for solution-processed solar cells, lasers, light-emitting diodes (LEDs), and X-ray imaging applications. $^{1-8}$ Operating the hybrid perovskite-based photoelectronic devices involves several photophysical processes, such as photogenerated exciton dissociation, appearance of hot carriers and free carriers, and large polaron formation and migration. ${ }^{9-13}$ The slow cooling of hot carriers (HCs) created by above-band-gap laser excitation is a critical photophysical process in order to achieve highly efficient HC solar cells that operate beyond the Shockley-Queisser efficiency limit. ${ }^{14-17}$ On the other hand, in the LEDs, the fast HC relaxation is favored due to the competition between charge carrier trapping processes at high level energy and $\mathrm{HC}$ cooling dynamics. Therefore, providing an avenue to tune the $\mathrm{HC}$ cooling rate is important for improving the optoelectronic performance of HC-based hybrid perovskite devices. ${ }^{18,19}$ Polycrystalline thin films of the prototype three-dimensional (3D) hybrid perovskite $\mathrm{MAPbI}_{3}$ were reported to have slow $\mathrm{HC}$ dynamics with a $\sim 400$ fs cooling time because of auger heating effects and a hot phonon bottleneck. ${ }^{11,14,15,18,20}$ Recent experimental and theoretical studies suggest that the $\mathrm{HC}$ cooling time in perovskite materials can be effectively adjusted by compositional engineering, such as the mixing of cations, halogen atoms, and heavy metals. ${ }^{21-25}$

Received: May 25, 2019

Accepted: October 15, 2019

Published: October 15, 2019 
Two-dimensional (2D) Ruddlesden-Popper (RP) hybrid perovskites have obtained much attention as an alternative to $3 \mathrm{D}$ hybrid perovskites because of their improved stability and moisture resistance. The dimensionality reduction from $3 \mathrm{D}$ to $2 \mathrm{D}$ enables tuning the electronic and optical properties of hybrid perovskites through dielectric and quantum confinement effects related to the organic spacers. ${ }^{26,27}$ However, the specific influence of organic spacers on the HC cooling processes in $2 \mathrm{D} \mathrm{RP}$ hybrid perovskites, especially in the singlecrystal form, has not been investigated. A comprehensive study of the role of organic spacers on HC cooling dynamics in $2 \mathrm{D}$ $\mathrm{RP}$ hybrid perovskite single crystals proves to be important not only to better characterize the photophysical processes in this promising class of materials but also to keep enhancing the performance of HC-based optoelectronic devices using 2D RP hybrid perovskites.

Here, we explore and decipher the hot carrier dynamics in single crystals of $2 \mathrm{D} \mathrm{RP}$ hybrid perovskites containing different organic spacers, $(\mathrm{EA})_{2} \mathrm{PbI}_{4}\left(\mathrm{EA}=\mathrm{HOC}_{2} \mathrm{H}_{4} \mathrm{NH}_{3}{ }^{+}\right),(\mathrm{AP})_{2} \mathrm{PbI}_{4}$ $\left(\mathrm{AP}=\mathrm{HOC}_{3} \mathrm{H}_{6} \mathrm{NH}_{3}{ }^{+}\right)$, and $(\mathrm{PEA})_{2} \mathrm{PbI}_{4} \quad(\mathrm{PEA}=$ $\mathrm{C}_{6} \mathrm{H}_{5} \mathrm{C}_{2} \mathrm{H}_{4} \mathrm{NH}_{3}^{+}$) (see Figures 1 and $\mathrm{S} 1$ ), by combining the
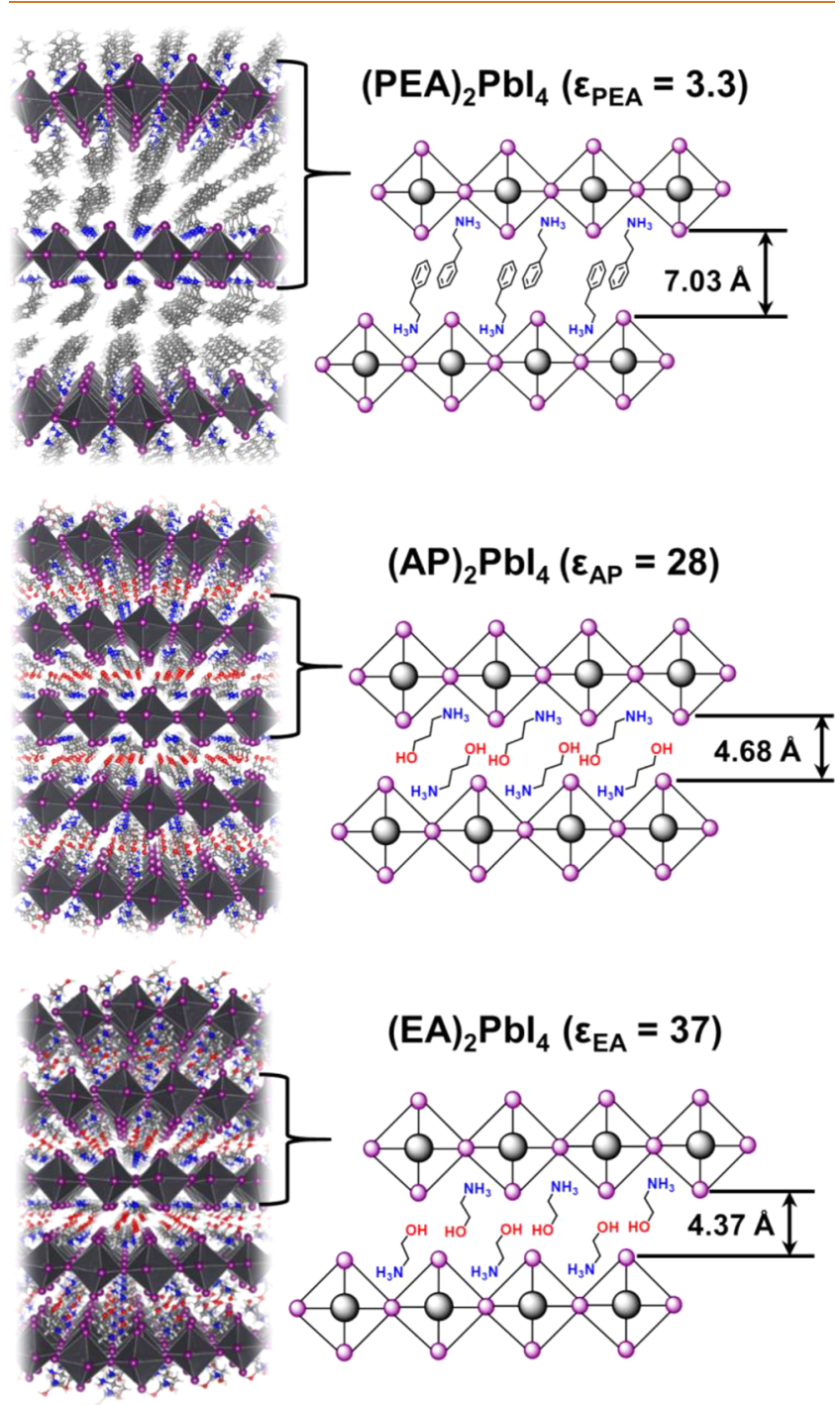

Figure 1. Schematic illustrations of $(\mathrm{PEA})_{2} \mathrm{PbI}_{4} \quad(\mathrm{PEA}=$ $\left.\mathrm{C}_{6} \mathrm{H}_{5} \mathrm{C}_{2} \mathrm{H}_{4} \mathrm{NH}_{3}{ }^{+}\right),(\mathrm{AP})_{2} \mathrm{PbI}_{4}\left(\mathrm{AP}=\mathrm{HOC}_{3} \mathrm{H}_{6} \mathrm{NH}_{3}^{+}\right)$, and $(\mathrm{EA})_{2} \mathrm{PbI}_{4}\left(\mathrm{EA}=\mathrm{HOC}_{2} \mathrm{H}_{4} \mathrm{NH}_{3}{ }^{+}\right)$single crystals. femtosecond transient reflectance (TR) spectroscopy measurements and time-domain $a b$ initio calculations. We find a strong dependence of the dielectric confinement of the organic spacers on the $\mathrm{HC}$ relaxation dynamics in these $2 \mathrm{D}$ perovskite crystals. Here, increasing the dielectric constant of the organic spacer slows down the HC dynamics by a factor of 4 because of a stronger screening of the Coulomb interactions and a weaker nonadiabatic coupling. We also describe the phonon modes that participate in the $\mathrm{HC}$ dynamics and suggest that the strong electron-phonon coupling induced by interactions between the inorganic layers and organic spacers can accelerate the dynamics of $\mathrm{HC}$ cooling.

\section{RESULTS}

The 2D hybrid perovskite single crystals were synthesized using our reported cooling method ${ }^{28}$ (see the experimental details in the Supporting Information). The crystallographic parameters and atomic coordinates are given in Tables S1-S6. The three 2D RP perovskite crystals show similar quantum confinement features, as their unit cell consists of a single inorganic layer $(n=1)$ and similar band gaps (the band gap difference between $(\mathrm{AP})_{2} \mathrm{PbI}_{4}$ and $(\mathrm{EA})_{2} \mathrm{PbI}_{4}$ is only $\sim 0.1 \mathrm{eV}$; see the absorption and photoluminescence spectra in Figure $\mathrm{S} 2)$. In contract, $(\mathrm{PEA})_{2} \mathrm{PbI}_{4}$ has a much smaller dielectric constant of its organic spacer layer $\left(\varepsilon_{\mathrm{PEA}}=3.3\right)$ and a larger distance between the inorganic layers $(d=7.03 \AA)$ than those in $(\mathrm{AP})_{2} \mathrm{PbI}_{4}\left(\varepsilon_{\mathrm{AP}}=28, d=4.68 \AA\right)$ and $(\mathrm{EA})_{2} \mathrm{PbI}_{4}\left(\varepsilon_{\mathrm{EA}}=37\right.$, $d=4.37 \AA)$, leading to a much larger exciton binding energy of $(\mathrm{PEA})_{2} \mathrm{PbI}_{4}(300 \mathrm{meV})$ compared to that of $(\mathrm{EA})_{2} \mathrm{PbI}_{4}(13$ $\mathrm{meV}){ }^{28}$ Such dielectric confinement originating from the different polarization of the inorganic layers and organic spacers is expected to strongly influence the intraband relaxations of hot carriers in the $2 \mathrm{D}$ hybrid perovskite crystals.

The femtosecond TR spectra and kinetics of (PEA) $)_{2} \mathrm{PbI}_{4}$, $(\mathrm{AP})_{2} \mathrm{PbI}_{4}$, and $(\mathrm{EA})_{2} \mathrm{PbI}_{4}$ were measured with a low pump fluence $\left(\sim 3 \mu \mathrm{J} \cdot \mathrm{cm}^{-2}\right.$, to minimize Auger recombination) and are shown in Figure 2. For (PEA) $)_{2} \mathrm{PbI}_{4}$, following the aboveband-edge excitation at $330 \mathrm{~nm}$, we observe a negative groundstate bleaching (GSB) signal $(-\Delta R / R<0)$ between 470 and $500 \mathrm{~nm}$ and a strong positive photoinduced absorption (PIA) band $(-\Delta R / R>0)$ centered at $511 \mathrm{~nm}$. As excess energy excitation creates hot carriers above the band edge, a pronounced rise of GSB at early time delay is observed, which could be attributed to the cooling of hot carriers from higher electronic states to the band edge; ${ }^{29,30}$ the intraband relaxation time here is $260 \pm 12$ fs. The decay time of the PIA signal (Figure S3) matches the GSB signal at longer delay times using both 330 and $480 \mathrm{~nm}$ excitations. Thus, the GSB rise and PIA decay are the result of the photogenerated carriers reaching the band edge from the initial thermalization. The decay of GSB at longer delay times is assigned to the electronhole recombination after cooling (i.e., interband relaxation with lifetimes $\tau_{1}=9$ ps and $\tau_{2}=75$ ps; see Figure S4). However, following band-edge $(480 \mathrm{~nm})$ excitation, the formation of GSB is instantaneous below the instrument-limited rise time $(<120 \mathrm{fs})$, and the average recovery time of GSB is longer than that at $330 \mathrm{~nm}$ excitation ( $23 \mathrm{ps} v s 34 \mathrm{ps}$ ). This confirms that, when using high-energy excitation, the hot carriers undergo thermal relaxation first and then thermalized carrier recombination occurs.

The $(\mathrm{AP})_{2} \mathrm{PbI}_{4}$ and $(\mathrm{EA})_{2} \mathrm{PbI}_{4}$ crystals show analogous TR spectra and kinetic features following the same excitation energies: (i) a rise of the GSB signal between 470 and $510 \mathrm{~nm}$ 

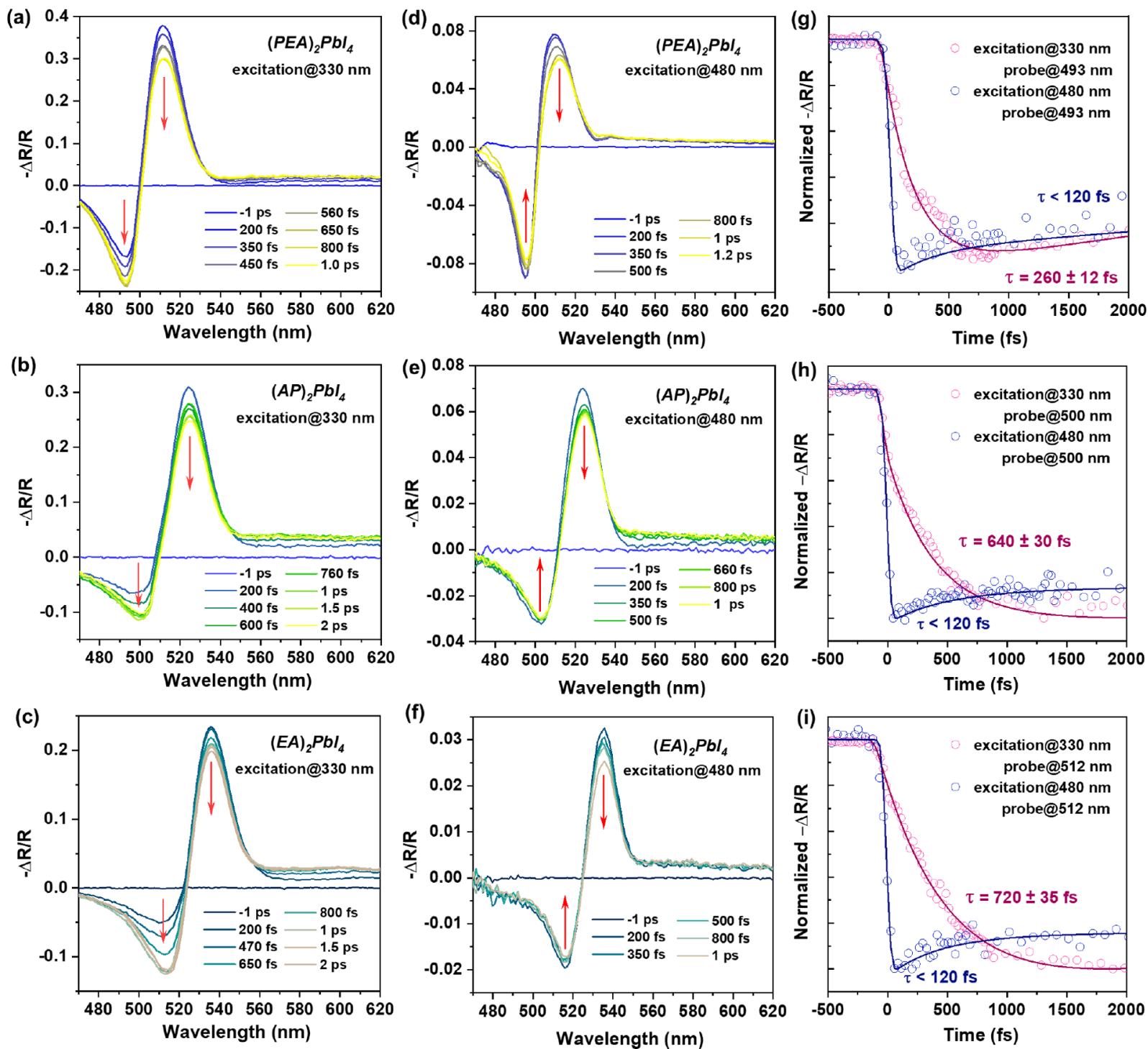

Figure 2. Transient reflectance spectra of $(\mathrm{PEA})_{2} \mathrm{PbI}_{4},(\mathrm{AP})_{2} \mathrm{PbI}_{4}$, and $(\mathrm{EA})_{2} \mathrm{PbI}_{4}$ crystals at early delay times (up to 2 ps) with excitation wavelengths of $(\mathrm{a}-\mathrm{c}) 330 \mathrm{~nm}$ and $(\mathrm{d}-\mathrm{f}) 480 \mathrm{~nm}$; normalized transient reflectance kinetics of $(\mathrm{g})(\mathrm{PEA})_{2} \mathrm{PbI}_{4} \mathrm{crystal}$ probed at $493 \mathrm{~nm},(\mathrm{~h})$ $(\mathrm{AP})_{2} \mathrm{PbI}_{4}$ crystal probed at $500 \mathrm{~nm}$, and (i) $(\mathrm{EA})_{2} \mathrm{PbI}_{4}$ crystal probed at $512 \mathrm{~nm}$ following 330 and $480 \mathrm{~nm}$ excitations (the solid lines represent fitting of the data with an exponential function).

and a decay of the PIA band centered at 524 and $535 \mathrm{~nm}$; (ii) an instantaneous formation of GSB ( $<120 \mathrm{fs}$ ) using band-edge excitation; and (iii) a longer lifetime of the GSB signal and PIA signal using both excitations compared to that of $(\mathrm{PEA})_{2} \mathrm{PbI}_{4}$ (Figures S3 and S4). All of these findings suggest that the lower exciton binding energy of $(\mathrm{EA})_{2} \mathrm{PbI}_{4}$ containing a larger dielectric constant of the organic spacer facilitates the exciton dissociation into free charge carriers at room temperature. Interestingly, the $(\mathrm{EA})_{2} \mathrm{PbI}_{4}$ crystal, on the other hand, shows a rise time of GSB $(720 \pm 35 \mathrm{fs})$ much longer than that of $(\mathrm{AP})_{2} \mathrm{PbI}_{4}(640 \pm 30 \mathrm{fs})$ using above-band-edge excitation, indicating a much slower hot carrier cooling rate in $(\mathrm{EA})_{2} \mathrm{PbI}_{4}$ compared to those of $(\mathrm{AP})_{2} \mathrm{PbI}_{4}$ and $(\mathrm{PEA})_{2} \mathrm{PbI}_{4}$. In addition, the $(\mathrm{AP})_{2} \mathrm{PbI}_{4}$ and $(\mathrm{EA})_{2} \mathrm{PbI}_{4}$ crystals show the slower electron-hole recombination after cooling (i.e., interband recombination dynamics) due to the larger screening of the Coulomb interactions induced by the larger dielectric constant of organic spacers and reduced electron-phonon coupling that will be discussed in detail later. It should be noted that the HC cooling time in $(\mathrm{EA})_{2} \mathrm{PbI}_{4}$ is shorter than that in the $\mathrm{MAPbI}_{3}$ crystal when using the same excess energy excitation $(\sim 1100$ fs; see the TR spectra and kinetics in Figure S5). ${ }^{10,14}$ This agrees well with previous theoretical predictions showing that a hot electron relaxation in $2 \mathrm{D}$ hybrid perovskites faster than that in $\mathrm{MAPbI}_{3}{ }^{31}$

To understand the effects of the organic spacers on the relaxation process of hot charge carriers and the slower intraband relaxation rate observed in the (EA) $)_{2} \mathrm{PbI}_{4}$ crystal, we performed nonadabatic molecular dynamics (NAMD) simulations with the fewest-switches surface hopping method and taking account spin-orbit coupling (SOC), as relativistic effects are expected to accelerate the intraband relaxation processes of perovskite systems. ${ }^{32-35}$ This is also confirmed by our calculations on 3D $\mathrm{MAPbI}_{3}$ without and with SOC (see the comparisons of charge population decays in Figure S6). The $2 \mathrm{D}$ hybrid perovskites display a direct band gap of $2.12 \mathrm{eV}$ at the $\Gamma$-point for $(\mathrm{PEA})_{2} \mathrm{PbI}_{4}$, of $2.06 \mathrm{eV}$ at the $\mathrm{B}$-point for $(\mathrm{AP})_{2} \mathrm{PbI}_{4}$, and of $2.29 \mathrm{eV}$ at the Z-point for $(\mathrm{EA})_{2} \mathrm{PbI}_{4}$ 
(a)

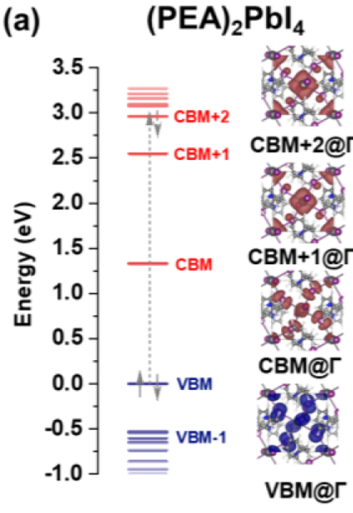

(b)

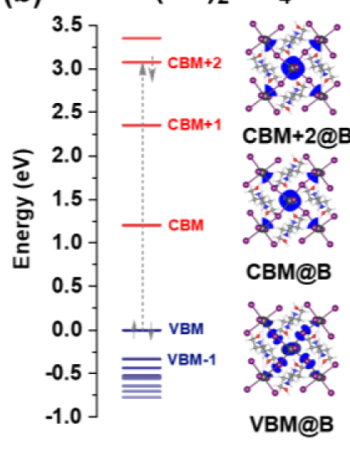

(c) $\quad(\mathrm{EA})_{2} \mathrm{Pbl}_{4}$

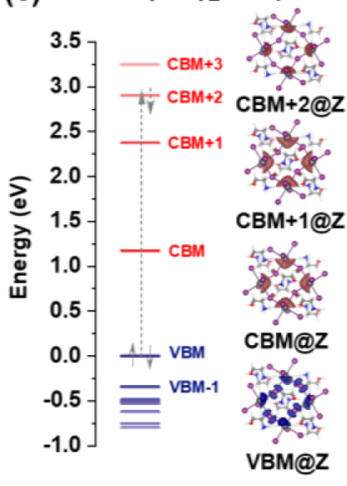

(d)

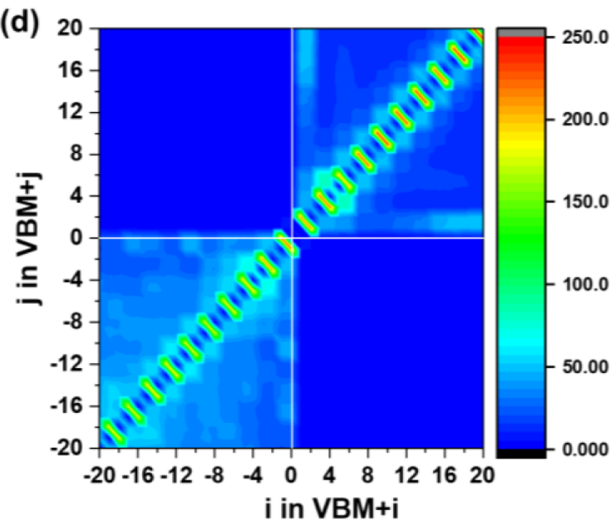

(e)

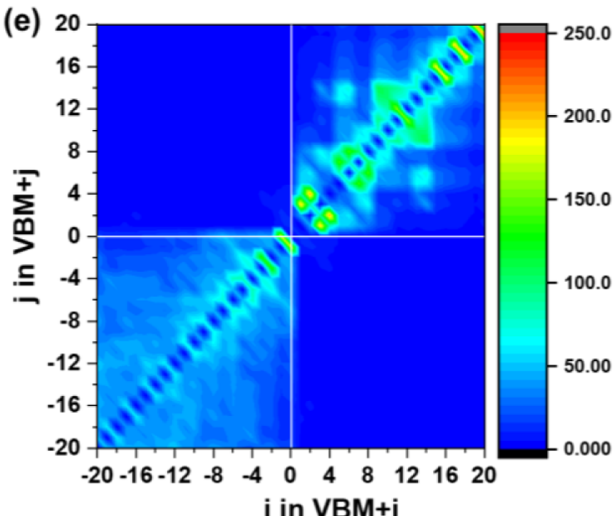

(f)

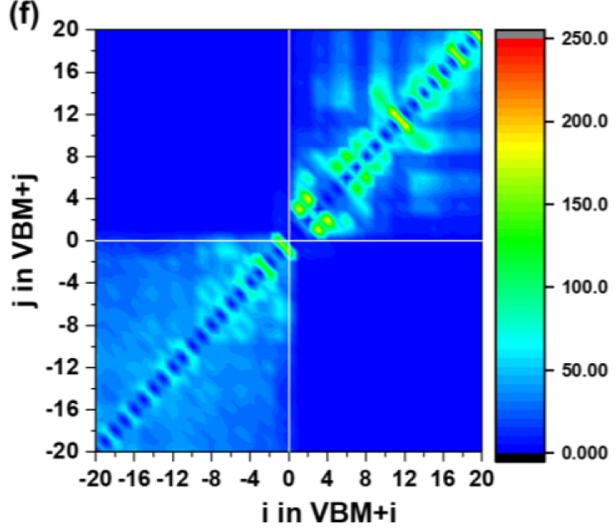

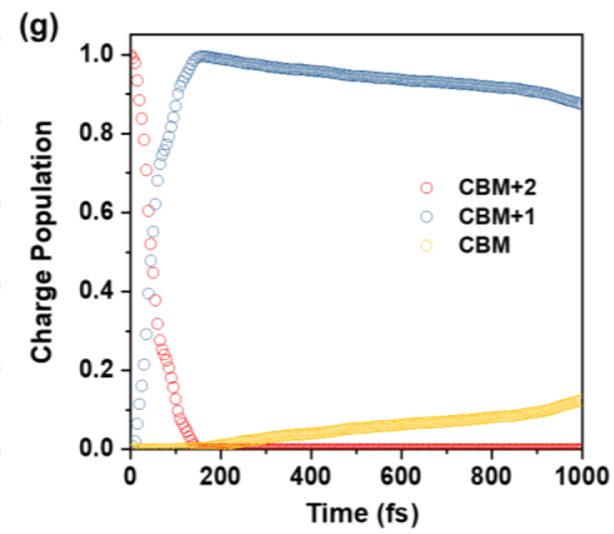
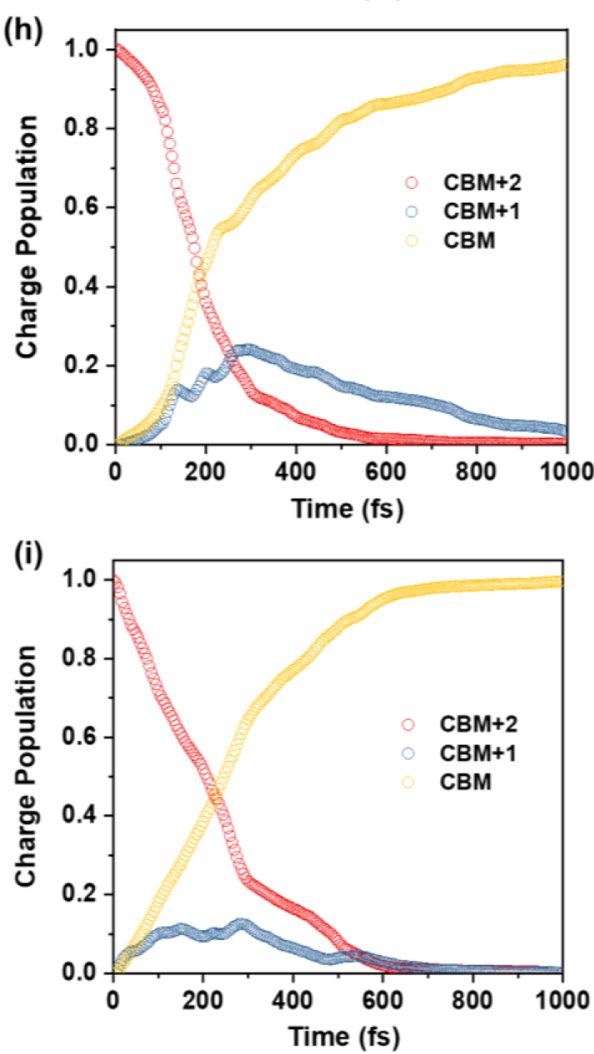

Figure 3. $(\mathrm{a}-\mathrm{c})$ Calculated energy levels of $(\mathrm{PEA})_{2} \mathrm{PbI}_{4}$ at the $\Gamma$-point, of $(\mathrm{AP})_{2} \mathrm{PbI}_{4}$ at the $\mathrm{B}$-point, and of $(\mathrm{EA})_{2} \mathrm{PbI}_{4}$ at the $\mathrm{Z}$-point, together with their electronic charge densities (the VBM is set to zero energy). (d-f) Average nonadiabatic couplings between high-energy levels obtained from NAMD calculations with SOC. $(\mathrm{g}-\mathrm{i})$ Time evolution of hot electron relaxation starting from the $\mathrm{CBM}+2(1.63 \mathrm{eV}$ above the $\mathrm{CBM})$ for $(\mathrm{PEA})_{2} \mathrm{PbI}_{4}$, from the $\mathrm{CBM}+2(1.87 \mathrm{eV}$ above the $\mathrm{CBM})$ for $(\mathrm{AP})_{2} \mathrm{PbI}_{4}$, and from the $\mathrm{CBM}+2(1.73 \mathrm{eV}$ above the $\mathrm{CBM})$ for (EA) $)_{2} \mathrm{PbI}_{4}$. All calculations were performed at the GGA/PBE level with SOC.

without SOC, whereas including SOC decreases the gaps by $\sim 0.9 \mathrm{eV}$, essentially through shifting the conduction band minimum (Figure S7). Given that the effective masses of the hot electrons are smaller than the hot holes in both perovskites and as the electronic bands in the deep-energy region (lower than $-3.5 \mathrm{eV}$ in Figure S7) are almost flat, only the hot electron cooling process was considered in the NAMD calculations. Without considering SOC effects (Figure S8), we observed a decay of the electron population down to $10 \%$ within $360 \mathrm{fs}$ from the initial CBM+10 (1.466 eV above the $\mathrm{CBM})$ in (PEA) ${ }_{2} \mathrm{PbI}_{4}$ and a slower decay within $1000 \mathrm{ps}$ from the initial $\mathrm{CBM}+3(1.644 \mathrm{eV}$ above the $\mathrm{CBM})$ in $(\mathrm{AP})_{2} \mathrm{PbI}_{4}$ and $\mathrm{CBM}+3(1.470 \mathrm{eV}$ above the $\mathrm{CBM})$ in $(\mathrm{EA})_{2} \mathrm{PbI}_{4}$.

When SOC effects are included, the electrons in (PEA) ${ }_{2} \mathrm{PbI}_{4}$ undergo fast relaxation from the initial $\mathrm{CBM}+2(1.63 \mathrm{eV}$ above the $\mathrm{CBM}$ ) to $\mathrm{CBM}+1$, and the population of electrons in the initial state rapidly decays to $10 \%$ of the initial population within $120 \mathrm{fs}$ (Figure $3 \mathrm{~g}$ ) due to a large nonadiabatic coupling (NAC): $\mathrm{NAC}[\langle\mathrm{CBM}+2 \mid \mathrm{CBM}+1\rangle]=216 \mathrm{meV}$; this agrees well with the lifetime of hot carrier relaxation deduced from the femtosecond TR kinetics of (PEA) $)_{2} \mathrm{PbI}_{4}$ ( $\left.\sim 220 \mathrm{fs}\right)$. In the present case, the direct population transfer between the initial $\mathrm{CBM}+2$ and $\mathrm{CBM}$ is less favorable because of the small NAC between these two states $(\mathrm{NAC}[\langle\mathrm{CBM}+2 \mid \mathrm{CBM}\rangle]=45 \mathrm{meV})$. Note that there occurs no charge transfer from the organic spacers to the inorganic layers as the charge density of $\mathrm{CBM}+2$ in $(\mathrm{PEA})_{2} \mathrm{PbI}_{4}$ is delocalized within the inorganic layer (Figure $3 a)$. However, in the case of $(\mathrm{AP})_{2} \mathrm{PbI}_{4}$ and $(\mathrm{EA})_{2} \mathrm{PbI}_{4}$, the hot electrons need a much longer time to cool down from the initial $\mathrm{CBM}+2$ to the $\mathrm{CBM}$, as direct population transfer is 
(a)

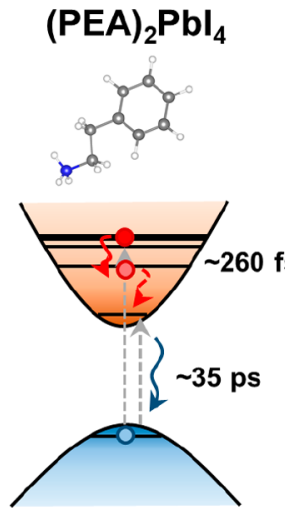

(b)

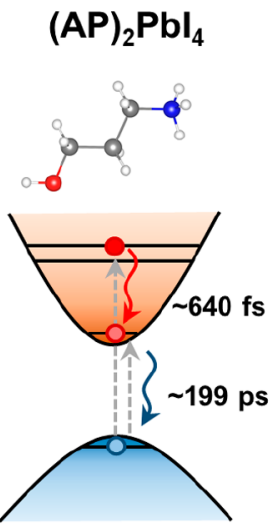

(c)

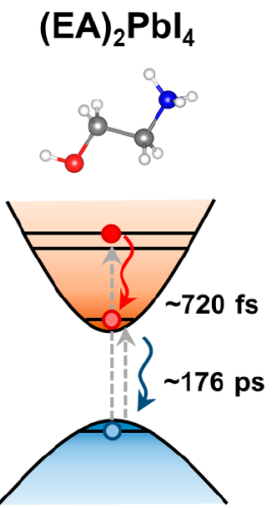

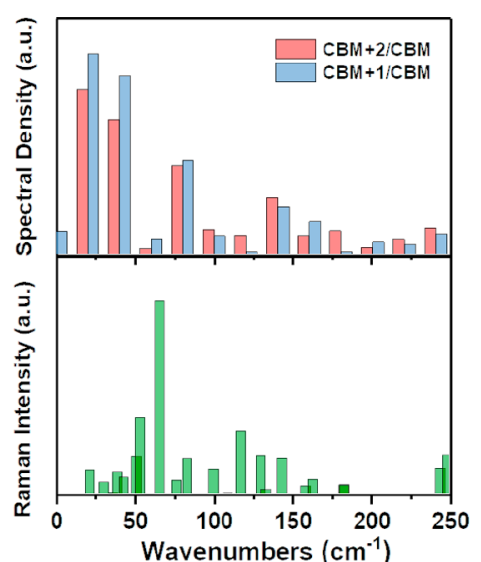
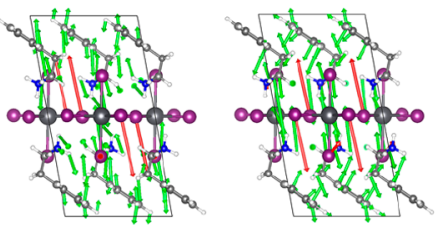

$21.5 \mathrm{~cm}^{-1}$

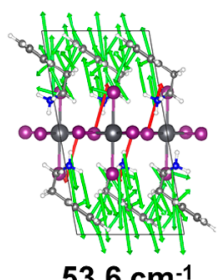

$43.2 \mathrm{~cm}^{-1}$

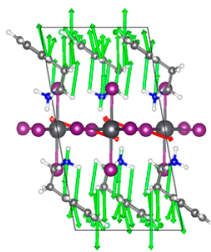

$117.7 \mathrm{~cm}^{-1}$
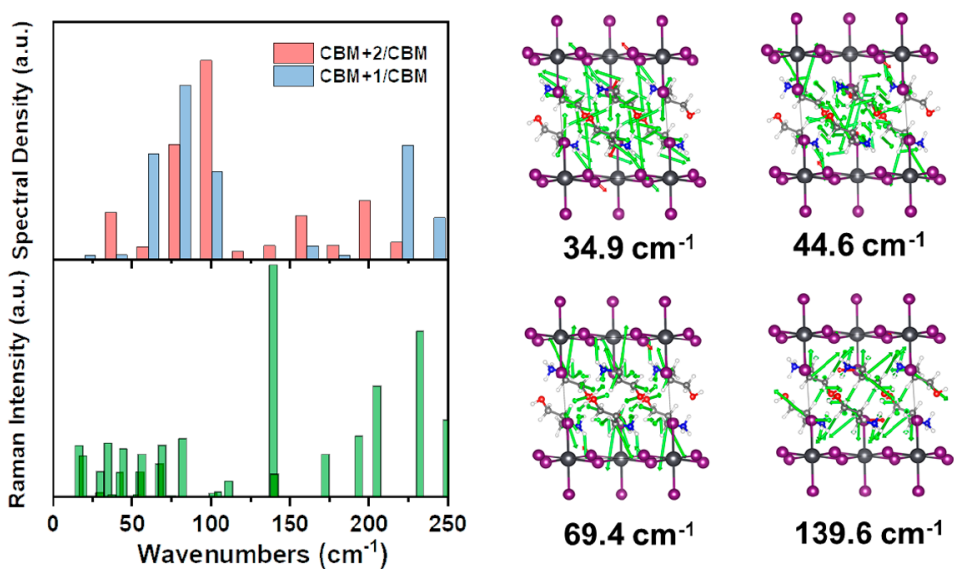

$69.4 \mathrm{~cm}^{-1}$

$139.6 \mathrm{~cm}^{-1}$

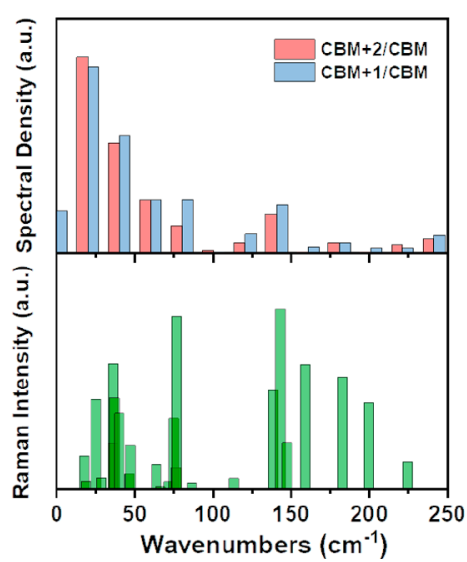

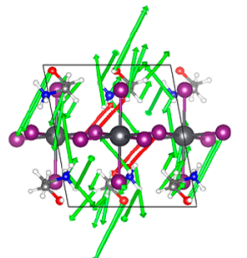

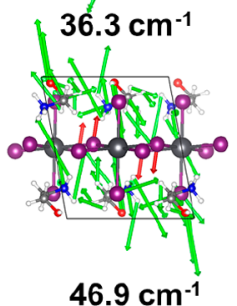

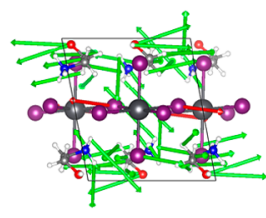

$40.3 \mathrm{~cm}^{-1}$

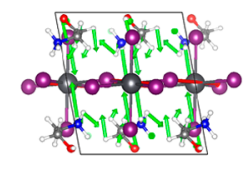

$75.4 \mathrm{~cm}^{-1}$

Figure 4. Hot electron relaxation and electron-hole pair recombination processes after high-energy excitation, spectral density between pair states for hot electron relaxation (top panel), and calculated Raman peaks (bottom panel) of (a) $\left(\mathrm{PEA}_{2} \mathrm{PbI}_{4},(\mathrm{~b})(\mathrm{AP})_{2} \mathrm{PbI}_{4}\right.$, and $(\mathrm{c})$ $(\mathrm{EA})_{2} \mathrm{PbI}_{4}$, together with selected vibrational normal modes (displacement vectors of inorganic layer and organic spacer are indicated by red and green arrows, respectively).

most likely to occur between these two states $(\mathrm{NAC}[\langle\mathrm{CBM}+21$ $\mathrm{CBM}\rangle]=176 \mathrm{meV}$ for $(\mathrm{AP})_{2} \mathrm{PbI}_{4}$ and $198 \mathrm{meV}$ for $\left.(\mathrm{EA})_{2} \mathrm{PbI}_{4}\right)$; the population of hot electrons decays to $10 \%$ of its initial value within $\sim 360 \mathrm{fs}$ for $(\mathrm{AP})_{2} \mathrm{PbI}_{4}$ and $\sim 500 \mathrm{fs}$ for $(\mathrm{EA})_{2} \mathrm{PbI}_{4}$ (Figure $\left.3 \mathrm{~h}, \mathrm{i}\right)$, which are again in agreement with the hot carrier relaxation times of $(\mathrm{AP})_{2} \mathrm{PbI}_{4}(\sim 640 \mathrm{fs})$ and $(\mathrm{EA})_{2} \mathrm{PbI}_{4}(\sim 720 \mathrm{fs})$. Note that in $(\mathrm{EA})_{2} \mathrm{PbI}_{4}$ the $\mathrm{HC}$ cooling process occurring at the symmetric Z-point shows a slower decay of hot electrons compared to that at the symmetric $\Gamma$ point (Figure S9).

Overall, the SOC effects can enhance the electron relaxation rates within the conduction bands because of two effects: ${ }^{35}$ (i) they could increase the average magnitudes of NACs between higher conduction bands (Figure $3 \mathrm{~d}-\mathrm{f}$ ) by including the two component functions that represent the superpositions of holes or electrons, compared to those obtained without SOC (Figure $\mathrm{S} 8 \mathrm{~d}-\mathrm{f}$ ); and (ii) the qualitative changes of the NAC structure include a substantial degree of coupling of states within conduction bands. The calculated time scales including SOC agree well with the experimental values derived from our femtosecond TR measurements. The NACs between the conduction band states in (PEA) ${ }_{2} \mathrm{PbI}_{4}$ are significantly larger than those in $(\mathrm{AP})_{2} \mathrm{PbI}_{4}$ and $(\mathrm{EA})_{2} \mathrm{PbI}_{4}$. Therefore, the fast hot electron relaxation among the conduction bands in 
(PEA) $)_{2} \mathrm{PbI}_{4}$ is due at least partly to the larger NAC induced by the overlapping of the electronic charge density between these conduction bands (Figure $3 \mathrm{a}-\mathrm{c}$ ) and the larger density of states in the high-energy region compared to that of $(\mathrm{AP})_{2} \mathrm{PbI}_{4}$ and $(\mathrm{EA})_{2} \mathrm{PbI}_{4}$ (Figure $\mathrm{S} 10$ ).

To better understand the effects of carrier interactions with the lattice modes on the hot carrier cooling processes in $(\mathrm{PEA})_{2} \mathrm{PbI}_{4},(\mathrm{AP})_{2} \mathrm{PbI}_{4}$, and $(\mathrm{EA})_{2} \mathrm{PbI}_{4}$, we calculated the phonon modes via Fourier transformation of the fluctuations in the energy differences between pairs of conduction bands (top panel in Figure 4) as well as the Raman peaks and intensities at the density functional perturbation theory level (bottom panel in Figure 4). We find that the low-frequency modes below $200 \mathrm{~cm}^{-1}$ dominate the spectral density for the $\mathrm{HC}$ relaxation processes in $2 \mathrm{D} \mathrm{RP}$ perovskite crystals; by visualizing the vibration vectors as given in Figure 4, these modes can be ascribed to the horizontal $\mathrm{Pb}-\mathrm{I}$ stretching modes and vertical $\mathrm{I}-\mathrm{Pb}-\mathrm{I}$ rocking modes of the inorganic layer together with vibrational modes of the organic spacers, which are in a good agreement with previous assignments. ${ }^{36,37}$ As in $2 \mathrm{D}$ perovskites the organic spacers are predominantly coupled to the stretching/rocking vibrations of the inorganic layers, these low-energy "hybrid phonon" modes can accelerate the hot carrier cooling processes in comparison to $3 \mathrm{D} \mathrm{MAPbI}_{3}$ in which the $\mathrm{HC}$ relaxation couples only little to the organic cations. The HC relaxations in hybrid perovskites are also associated with the magnitudes of the exciton binding energy ${ }^{38}$ and electron-phonon couplings, ${ }^{18,39}$ in particular, the interactions between the longitudinal optical (LO) phonons and electrons, which can be described by the Fröhlich parameter $\alpha$ (the $\alpha$ values are given in Table S7). (PEA) ${ }_{2} \mathrm{PbI}_{4}$ has a calculated $\alpha$ value (4.29) larger than that of $(\mathrm{AP})_{2} \mathrm{PbI}_{4}$ and $(\mathrm{EA})_{2} \mathrm{PbI}_{4}$ (3.68 and 3.82) due to its larger electron effective mass and smaller optical dielectric constant, which indicates that the electronic transitions among the conduction bands in (PEA) $)_{2} \mathrm{PbI}_{4}$ are coupled more strongly to the vibrations of the inorganic cages. Moreover, in $(\mathrm{EA})_{2} \mathrm{PbI}_{4}$, the Coulomb interactions among excited charge carriers are better screened as the EA spacer has a larger dielectric constant; in (PEA) $)_{2} \mathrm{PbI}_{4}$, these interactions are less screened, which leads to a more significant scattering of the charge carriers among themselves and with optical phonons. In addition, the two sets of hydrogen bonding patterns (i.e., $\mathrm{N}-\mathrm{H} \cdots \mathrm{I}$ at $2.62 \AA$ and $\mathrm{O}-$ $\mathrm{H} \cdots \mathrm{I}$ at $2.71 \AA$ ) formed between the EA spacers and the $\left[\mathrm{PbI}_{4}\right]^{2-}$ layers are expected to prevent the rotational motions of the EA molecules, which can also contribute to the slower $\mathrm{HC}$ cooling dynamics in $(\mathrm{EA})_{2} \mathrm{PbI}_{4}{ }^{24}$

\section{CONCLUSION}

We have demonstrated that the dielectric constant of the spacer significantly affects the HC cooling process in $2 \mathrm{D}$ hybrid perovskite crystals. Our experimental and theoretical results indicate that the increase in the $\mathrm{HC}$ cooling time in (EA) $)_{2} \mathrm{PbI}_{4}$ with respect to $(\mathrm{PEA})_{2} \mathrm{PbI}_{4}$ can be attributed to (i) a stronger screening of the Coulomb interactions; (ii) reduced nonradiative couplings among the conduction bands; (iii) smaller electron-LO phonon couplings; and (iv) suppressed rotations of the organic spacers. Our results provide variable components to design low-dimensional hybrid perovskite materials with organic spacers that can prolong the carrier cooling dynamics.

\section{METHODS}

2D Hybrid Perovskite Single-Crystal Preparation. (EA) ${ }_{2} \mathrm{PbI}_{4}$ : $1.5 \mathrm{~g}$ of $\mathrm{PbI}_{2}$ powder $(99 \%)$ and $0.8 \mathrm{~mL}$ of $\mathrm{HOC}_{2} \mathrm{H}_{4} \mathrm{NH}_{2}$ liquid (99\%) were added in $14 \mathrm{~mL}$ of $57 \% \mathrm{HI}$ in a $20 \mathrm{~mL}$ vial as a precursor; the precursor was cooled to $3.7^{\circ} \mathrm{C}$ from room temperature in $6 \mathrm{~h}$. $(\mathrm{AP})_{2} \mathrm{PbI}_{4}: 2.23 \mathrm{~g}$ of $\mathrm{PbO}$ powder (99\%) was dissolved in $10 \mathrm{~mL}$ of $57 \% \mathrm{HI}$ in a $20 \mathrm{~mL}$ vial and stirred at $100{ }^{\circ} \mathrm{C}$ for $15 \mathrm{~min}$; then the solution was cooled to room temperature, and $2.7 \mathrm{~mL}$ of $\mathrm{HOC}_{3} \mathrm{H}_{6} \mathrm{NH}_{2}$ liquid (99\%) was added in the same vial; after that, the clear solution was cooled to $-20{ }^{\circ} \mathrm{C}$ from room temperature in 8 $\mathrm{h}$ and left at $-20^{\circ} \mathrm{C}$ for 1 week to obtain the $(\mathrm{AP})_{2} \mathrm{PbI}_{4}$ single crystal. (PEA) $)_{2} \mathrm{PbI}_{4}: 1.0 \mathrm{~g}$ of $\mathrm{PbI}_{2}$ powder $(99 \%)$ and $0.2 \mathrm{~mL}$ of $\mathrm{C}_{6} \mathrm{H}_{5} \mathrm{C}_{2} \mathrm{H}_{4} \mathrm{NH}_{3}$ liquid (99\%) were added in $10 \mathrm{~mL}$ of $57 \% \mathrm{HI}$ in a $20 \mathrm{~mL}$ vial as a precursor; the precursor was heated to $90.0{ }^{\circ} \mathrm{C}$ from room temperature to fully dissolve the reactants; then the heated precursor was cooled to room temperature in $6 \mathrm{~h}$. To exclude the interference from any surface defects or traps, we have cleaved the smooth surface of the $2 \mathrm{D}$ perovskite crystals after checking their crystallographic plane for the transient reflectance measurements.

X-ray Structure Analysis. We obtained the single-crystal intensity data with a Bruker APEX DUO following Mo $\mathrm{K} \alpha$ radiation (wavelength: $0.71073 \AA$ ) at $100 \mathrm{~K}$.

Femtosecond Transient Reflectance Spectroscopy. We performed the femtosecond transient reflectance spectroscopy measurements at time scales from 0.1 ps to $6 \mathrm{~ns}$ in the transient absorption spectrometer at room temperature (the details about the transient absorption (TA) setup can be found in ref 40). In this study, we used a Helios fs-TA spectrometer (Ultrafast Systems) equipped with UV-Vis-near-IR detectors. A few $\mu \mathrm{J} /$ pulse energy of the amplified $800 \mathrm{~nm}$ laser pulse, operating at repetition rate of $1 \mathrm{kHz}$, was made to pass through an optical parametric amplifier (Light Conversion) to create the optical excitation pulses at 330 and $480 \mathrm{~nm}$. The white-light probe pulses were generated by focusing a small fraction of the fundamental $800 \mathrm{~nm}$ pulses on a $2 \mathrm{~mm}$ sapphire plate. The white light probe pulse was divided into signal and reference for a better ratio of the signal-to-noise. The optical pump and optical probe pulses were guided and spatially overlapped on the surface of the $2 \mathrm{D}$ $\mathrm{RP}$ perovskite crystals. The absorption change $(\Delta A)$ was recorded by the Surface Xplorer software as a function of time delay $\left(t_{\mathrm{i}}\right)$ and wavelength $(\lambda, \mathrm{nm})$. Finally, the $\Delta R / R\left(t_{0}\right)$ was calculated using the equation $\Delta R / R\left(t_{0}\right)=10^{-\Delta A}-1$. The negative absorption features (i.e., $-\Delta R / R\left(t_{0}\right)<0$ ) and positive spectral features (i.e., $-\Delta R / R\left(t_{0}\right)>$ $0)$ indicate the photoinduced absorption and the photobleach, respectively, where $R\left(t_{0}\right)$ is the reflectance signal without excitation pulse and $R\left(t_{\mathrm{i}}\right)$ is the reflectance signal with excitation pulse at time delay $t_{\mathrm{i}}$. Here, we fixed the optical excitation fluence at $\sim 3 \mu \mathrm{J} / \mathrm{cm}^{2}$ to exclude the effect of multiple charge carrier generation. Considering the excited beam spot size (diameter) of $\sim 0.04 \mathrm{~cm}$, we calculated the fluence of the pump pulse as follows: pump fluence $=\frac{E}{A}=\frac{3.8}{1.26 \times 10^{-3}}$ $\mathrm{nJ} / \mathrm{cm}^{2}=3.015 \mu \mathrm{J} / \mathrm{cm}^{2}$, where $E$ is the energy per pulse (measured power is $3.8 \mu \mathrm{W}$, pulse repetition rate $=1 \mathrm{kHz}$ ) and $A$ is the area of the beam spot $\left(\pi r^{2}, r\right.$ is the beam spot radius, $\left.0.02 \mathrm{~cm}\right)$.

Density Functional Theory (DFT) Calculations. DFT optimizations of the crystal structures of $\mathrm{MAPbI}_{3},(\mathrm{EA})_{2} \mathrm{PbI}_{4},(\mathrm{AP})_{2} \mathrm{PbI}_{4}$, and $(\mathrm{PEA})_{2} \mathrm{PbI}_{4}$ were carried out at the Perdew-Burke-Ernzerhof (PBE) level with the generalized gradient approximation (GGA) using the plane-wave self-consistent field (PWSCF) code in the Quantum ESPRESSO (QE) package. ${ }^{41}$ Starting from the experimental lattice parameters (Table $\mathrm{S} 1-\mathrm{S} 6$ ) of tetragonal-phase $\operatorname{MAPbI}_{3}(a=b=8.839 \AA, c=12.695 \AA),(E A)_{2} \operatorname{PbI}_{4}(a=10.226$ $\AA, b=9.045 \AA$, and $c=8.939 \AA),(\mathrm{AP})_{2} \mathrm{PbI}_{4}(a=10.781 \AA, b=9.228$ $\AA$, and $c=9.335 \AA$ ), and $(\mathrm{PEA})_{2} \mathrm{PbI}_{4}(a=8.687 \AA, b=8.690 \AA$ and $c$ $=16.424 \AA$ ), the optimized crystal parameters were obtained by relaxing both the cell parameters and the atomic positions. Ultrasoft pseudopotentials for $\mathrm{H}\left(1 \mathrm{~s}^{1}\right) ; \mathrm{C}, \mathrm{N}$, and $\mathrm{O}\left(2 \mathrm{~s}^{2}, 2 \mathrm{p}^{2}\right)$; I $\left(5 \mathrm{~s}^{2}, 5 \mathrm{p}^{2}\right)$; and $\mathrm{Pb}\left(5 \mathrm{~d}^{10}, 6 \mathrm{~s}^{2}, 6 \mathrm{p}^{2}\right)$ were used without and with consideration of spinorbit coupling (SOC). Uniform Brillouin zone grids of $6 \times 6 \times 6 \mathrm{k}$ mesh for $\mathrm{MAPbI}_{3},(\mathrm{EA})_{2} \mathrm{PbI}_{4}$, and $(\mathrm{AP})_{2} \mathrm{PbI}_{4}$ and of $6 \times 6 \times 3$ for $(\mathrm{PEA})_{2} \mathrm{PbI}_{4}$ were employed to calculated the band structures, as 
shown in Figure S6. Plane-wave basis set cutoff was 50 Ry for the wave functions and was $300 \mathrm{Ry}$ for the charge density. The crystal structures of all hybrid perovskites were fully relaxed (the total force on each atom $<0.01 \mathrm{eV} / \AA$ ) .

The Raman and far-infrared vibrational modes of $\mathrm{MAPbI}_{3}$, $(\mathrm{EA})_{2} \mathrm{PbI}_{4},(\mathrm{AP})_{2} \mathrm{PbI}_{4}$, and $(\mathrm{PEA})_{2} \mathrm{PbI}_{4}$, including mode positions and intensities, were calculated by using the Phonon code in the QE package. ${ }^{41,42}$ Here, the local density approximation functional together with norm-conserving pseudopotentials were used as this method can reproduce well the experimental vibrational spectra of hybrid perovskites. ${ }^{43}$ Plane-wave basis set cutoffs for the wave functions were $90 \mathrm{Ry}$. The uniform Monkhorst-Pack grids of $8 \times 8 \times$ 8 for $(\mathrm{EA})_{2} \mathrm{PbI}_{4}$ and $(\mathrm{AP})_{2} \mathrm{PbI}_{4}$ and $8 \times 8 \times 4$ for $(\mathrm{PEA})_{2} \mathrm{PbI}_{4}$ were used, and the self-consistency threshold was set at $10^{-14} \mathrm{Ry}$. Note that we did not include SOC in the phonon calculations because it has no significant role in the description of the vibrational features of hybrid perovskite systems.

Electron-Phonon Coupling Calculations. The electronphonon coupling was represented by the Fröhlich parameter $\alpha$, defined as $\alpha=\frac{1}{4 \pi \varepsilon_{0}} \frac{e^{2}}{\hbar}\left(\frac{1}{\varepsilon_{\infty}}-\frac{1}{\varepsilon_{s}}\right) \sqrt{\frac{m}{2 \hbar \omega}}$, where $e$ is the charge of the carrier; $\hbar$ is Planck's constant; $m$ is the electron effective mass; $\varepsilon_{0}$ is the vacuum dielectric permittivity; $\varepsilon_{\infty}$ is the optical dielectric constant; $\varepsilon_{\mathrm{s}}$ is the static dielectric constant, and $\omega$ is the LO phonon mode frequency. $\varepsilon_{\mathrm{s}}$ was calculated using linear-response method as implemented in the $\mathrm{QE}$ package. According to the ground-state electronic wave functions, the optical permittivity of $\mathrm{MAPbI}_{3}$, $(\mathrm{EA})_{2} \mathrm{PbI}_{4},(\mathrm{AP})_{2} \mathrm{PbI}_{4}$, and $(\mathrm{PEA})_{2} \mathrm{PbI}_{4}$ was obtained via the random-phase approximation method in the YAMBO code. ${ }^{44} \omega$ was calculated from the imaginary part of the inverse dielectric function $(\operatorname{Im}[1 / \varepsilon(\omega)])$ in the far-infrared region.

The dielectric function at far-infrared frequencies, as given in Figure S11 of the Supporting Information, was obtained using the following equation:

$$
\varepsilon(\omega)=1+\sum_{n=1, N_{\mathrm{ph}}} \frac{F_{n}^{2}}{\omega_{n}^{2}-(\omega+i \eta)^{2}}+\frac{F_{\mathrm{el}}^{2}}{\omega_{\mathrm{el}}^{2}-\left(\omega+i \eta_{\mathrm{el}}\right)^{2}}
$$

where $n$ is the index of $N_{\text {ph }}$ phonon modes; $\omega_{n}$ is the $n$th phonon frequency; $\omega_{\mathrm{el}}$ is the electronic band gap; $F_{\mathrm{n}}$ and $F_{\mathrm{el}}$ are the oscillator strength; and $\eta$ and $\eta_{\mathrm{el}}$ are the broadening factors $(0.01 \mathrm{eV}$ in our calculations). The phonon displacements and frequencies in the infrared region were calculated using the Phonon code with the QE package at the GGA/PBE level. The details of the calculations of the far-infrared dielectric function can be found in previously published works. ${ }^{10,45}$

Molecular Dynamics (MD) Simulations. Adiabatic ab initio MD simulations were carried out at the GGA/PBE level of theory by using ultrasoft pseudopotentials without and with account of SOC effects as implemented in the QE code. The optimized crystal structures of $\mathrm{MAPbI}_{3},(\mathrm{EA})_{2} \mathrm{PbI}_{4},(\mathrm{AP})_{2} \mathrm{PbI}_{4}$, and $(\mathrm{PEA})_{2} \mathrm{PbI}_{4}$ were considered as the starting geometries for the following adiabatic ab initio $\mathrm{MD}$ simulations. A 3000 fs trajectory with 1 fs time step was used, and the Andersen thermostat was used to keep the temperature at $300 \mathrm{~K}$.

Nonadiabatic MD calculations on $\mathrm{MAPbI}_{3},(\mathrm{EA})_{2} \mathrm{PbI}_{4},(\mathrm{AP})_{2} \mathrm{PbI}_{4}$, and $(\mathrm{PEA})_{2} \mathrm{PbI}_{4}$ were performed using the PYXAID2 code. ${ }^{46-48}$ The fewest-switches surface hopping ${ }^{49}$ implemented within time-dependent DFT has been applied to investigate the hybrid perovskite systems, ${ }^{50-52}$ from the time-dependent Schrödinger equation

$$
i \hbar \frac{\partial}{\partial t} \Psi_{n}(\mathbf{r}, t)=H(\mathbf{r}, \mathbf{R}, t) \Psi_{n}(\mathbf{r}, \mathrm{t})
$$

and Kohn-Sham orbitals

$$
\Psi_{n}(\mathbf{r}, \mathrm{t})=\sum_{k} C_{k}^{n}(t) \Phi_{k}(\mathbf{r} ; \mathbf{R},(t))
$$

After the solutions of these equations were obtained, the transition probability between adiabatic states was further calculated by the wave function expansion coefficients and corresponding couplings, which are defined as $d_{i j}=-i \hbar\left\langle\Phi_{i}\left|\frac{\partial}{\partial t}\right| \Phi_{j}\right\rangle$ (see the details of NAMD theory in refs 46 and 47).

\section{ASSOCIATED CONTENT}

\section{S Supporting Information}

The Supporting Information is available free of charge on the ACS Publications website at DOI: 10.1021/acsnano.9b04085.

Crystallographic parameters and atomic coordinates, optimized crystal structures, absorption spectra, transient reflectance kinetics of $2 \mathrm{D}$ hybrid perovskites, transient reflectance spectra and kinetics of $\mathrm{MAPbI}_{3}$ and calculated nonadiabatic couplings, and time evolution of hot electron relaxations (PDF)

\section{AUTHOR INFORMATION}

\section{Corresponding Author}

*E-mail: omar.abdelsaboor@kaust.edu.sa.

ORCID $\odot$

Jun Yin: 0000-0002-1749-1120

Partha Maity: 0000-0002-0293-7118

Rounak Naphade: 0000-0002-3504-8552

Jr-Hau He: 0000-0003-1886-9241

Osman M. Bakr: 0000-0002-3428-1002

Jean-Luc Brédas: 0000-0001-7278-4471

Omar F. Mohammed: 0000-0001-8500-1130

Author Contributions

${ }^{\perp}$ J.Y. and P.M. contributed equally.

\section{Notes}

The authors declare no competing financial interest.

\section{ACKNOWLEDGMENTS}

This work was supported by the King Abdullah University of Science and Technology (KAUST). The work at Georgia Tech was supported by the Georgia Research Alliance and the Vasser-Woolley Foundation. We acknowledge the Supercomputing Laboratory at KAUST for their computational and storage resources, as well as their gracious assistance. We also acknowledge Dr. J. Khan for the discussions.

\section{REFERENCES}

(1) McMeekin, D. P.; Mahesh, S.; Noel, N. K.; Klug, M. T.; Lim, J.; Warby, J. H.; Ball, J. M.; Herz, L. M.; Johnston, M. B.; Snaith, H. J. Solution-Processed All-Perovskite Multi-Junction Solar Cells. Joule 2019, 3, 387-401.

(2) Lu, M.; Zhang, Y.; Wang, S.; Guo, J.; Yu, W. W.; Rogach, A. L. Metal Halide Perovskite Light-Emitting Devices: Promising Technology for Next-Generation Displays. Adv. Funct. Mater. 2019, 29, 1902008.

(3) Cao, Y.; Wang, N. N.; Tian, H.; Guo, J. S.; Wei, Y. Q.; Chen, H.; Miao, Y. F.; Zou, W.; Pan, K.; He, Y. R.; Cao, H.; Ke, Y.; Xu, M. M.; Wang, Y.; Yang, M.; Du, K.; Fu, Z. W.; Kong, D. C.; Dai, D. X.; Jin, Y. Z.; et al. Perovskite Light-Emitting Diodes Based on Spontaneously Formed Submicrometre-Scale Structures. Nature 2018, 562, 249253.

(4) Xing, G. C.; Mathews, N.; Lim, S. S.; Yantara, N.; Liu, X. F.; Sabba, D.; Gratzel, M.; Mhaisalkar, S.; Sum, T. C. Low-Temperature Solution-Processed Wavelength-Tunable Perovskites for Lasing. Nat. Mater. 2014, 13, 476-480.

(5) Chen, Q. S.; Wu, J.; Ou, X. Y.; Huang, B. L.; Almutlaq, J.; Zhumekenov, A. A.; Guan, X. W.; Han, S. Y.; Liang, L. L.; Yi, Z. G.; Li, J.; Xie, X. J.; Wang, Y.; Li, Y.; Fan, D. Y.; Teh, D. B. L.; All, A. H.; 
Mohammed, O. F.; Bakr, O. M.; Wu, T.; et al. All-Inorganic Perovskite Nanocrystal Scintillators. Nature 2018, 561, 88-93.

(6) Zhang, Y. H.; Sun, R. J.; Ou, X. Y.; Fu, K. F.; Chen, Q. S.; Ding, Y. C.; Xu, L. J.; Liu, L. M.; Han, Y.; Malko, A. V.; Liu, X. G.; Yang, H. H.; Bakr, O. M.; Liu, H.; Mohammed, O. F. Metal Halide Perovskite Nanosheet for X-Ray High-Resolution Scintillation Imaging Screens. ACS Nano 2019, 13, 2520-2525.

(7) Pan, J.; Sarmah, S. P.; Murali, B.; Dursun, I.; Peng, W.; Parida, M. R.; Liu, J.; Sinatra, L.; Alyami, N.; Zhao, C.; Alarousu, E.; Ng, T. K.; Ooi, B. S.; Bakr, O. M.; Mohammed, O. F. Air-Stable SurfacePassivated Perovskite Quantum Dots for Ultra-Robust, Single- and Two-Photon-Induced Amplified Spontaneous Emission. J. Phys. Chem. Lett. 2015, 6, 5027-5033.

(8) Huang, H.; Bodnarchuk, M. I.; Kershaw, S. V.; Kovalenko, M. V.; Rogach, A. L. Lead Halide Perovskite Nanocrystals in the Research Spotlight: Stability and Defect Tolerance. ACS Energy Lett. 2017, 2, 2071-2083.

(9) D’Innocenzo, V.; Grancini, G.; Alcocer, M. J. P.; Kandada, A. R. S.; Stranks, S. D.; Lee, M. M.; Lanzani, G.; Snaith, H. J.; Petrozza, A. Excitons versus Free Charges in Organo-Lead Tri-Halide Perovskites. Nat. Commun. 2014, 5, 3586.

(10) Miyata, K.; Meggiolaro, D.; Trinh, M. T.; Joshi, P. P.; Mosconi, E.; Jones, S. C.; De Angelis, F.; Zhu, X. Y. Large Polarons in Lead Halide Perovskites. Sci. Adv. 2017, 3, No. e1701217.

(11) Xing, G. C.; Mathews, N.; Sun, S. Y.; Lim, S. S.; Lam, Y. M.; Gratzel, M.; Mhaisalkar, S.; Sum, T. C. Long-Range Balanced Electron- and Hole-Transport Lengths in Organic-Inorganic $\mathrm{CH}_{3} \mathrm{NH}_{3} \mathrm{PbI}_{3}$. Science 2013, 342, 344-347.

(12) Blancon, J. C.; Tsai, H.; Nie, W.; Stoumpos, C. C.; Pedesseau, L.; Katan, C.; Kepenekian, M.; Soe, C. M. M.; Appavoo, K.; Sfeir, M. Y.; Tretiak, S.; Ajayan, P. M.; Kanatzidis, M. G.; Even, J.; Crochet, J. J.; Mohite, A. D. Extremely Efficient Internal Exciton Dissociation through Edge States in Layered 2D Perovskites. Science 2017, 355, $1288-1291$.

(13) Miyata, K.; Atallah, T. L.; Zhu, X. Y. Lead Halide Perovskites: Crystal-Liquid Duality, Phonon Glass Electron Crystals, and Large Polaron Formation. Sci. Adv. 2017, 3, e1701469.

(14) Fu, J. H.; Xu, Q.; Han, G. F.; Wu, B.; Huan, C. H. A.; Leek, M. L.; Sum, T. C. Hot Carrier Cooling Mechanisms in Halide Perovskites. Nat. Commun. 2017, 8, 1300.

(15) Price, M. B.; Butkus, J.; Jellicoe, T. C.; Sadhanala, A.; Briane, A.; Halpert, J. E.; Broch, K.; Hodgkiss, J. M.; Friend, R. H.; Deschler, F. Hot-Carrier Cooling and Photoinduced Refractive Index Changes in Organic-Inorganic Lead Halide Perovskites. Nat. Commun. 2015, 6, 8420

(16) Shen, Q.; Ripolles, T. S.; Even, J.; Ogomi, Y.; Nishinaka, K.; Izuishi, T.; Nakazawa, N.; Zhang, Y. H.; Ding, C.; Liu, F.; Toyoda, T.; Yoshino, K.; Minemoto, T.; Katayama, K.; Hayase, S. Slow Hot Carrier Cooling in Cesium Lead Iodide Perovskites. Appl. Phys. Lett. 2017, 111, 153903.

(17) Li, M. J.; Bhaumik, S.; Goh, T. W.; Kumar, M. S.; Yantara, N.; Gratzel, M.; Mhaisalkar, S.; Mathews, N.; Sum, T. C. Slow Cooling and Highly Efficient Extraction of Hot Carriers in Colloidal Perovskite Nanocrystals. Nat. Commun. 2017, 8, 14350.

(18) Yang, Y.; Ostrowski, D. P.; France, R. M.; Zhu, K.; van de Lagemaat, J.; Luther, J. M.; Beard, M. C. Observation of a HotPhonon Bottleneck in Lead-Iodide Perovskites. Nat. Photonics 2016, $10,53-59$.

(19) Li, M.; Fu, J.; Xu, Q.; Sum, T. C. Slow Hot-Carrier Cooling in Halide Perovskites: Prospects for Hot-Carrier Solar Cells. Adv. Mater. 2019, 1802486.

(20) Dursun, I.; Maity, P.; Yin, J.; Turedi, B.; Zhumekenov, A. A.; Lee, K. J.; Mohammed, O. F.; Bakr, O. M. Why Are Hot Holes Easier to Extract Than Hot Electrons from Methylammonium Lead Iodide Perovskite? Adv. Energy Mater. 2019, 9, 1900084.

(21) Hopper, T. R.; Gorodetsky, A.; Frost, J. M.; Muller, C.; Lovrincic, R.; Bakulin, A. A. Ultrafast Intraband Spectroscopy of HotCarrier Cooling in Lead-Halide Perovskites. ACS Energy Lett. 2018, 3, 2199-2205.
(22) Chen, J.; Messing, M. E.; Zheng, K.; Pullerits, T. CationDependent Hot Carrier Cooling in Halide Perovskite Nanocrystals. J. Am. Chem. Soc. 2019, 141, 3532-3540.

(23) Chung, H.; Il Jung, S.; Kim, H. J.; Cha, W.; Sim, E.; Kim, D.; Koh, W. K.; Kim, J. Composition-Dependent Hot Carrier Relaxation Dynamics in Cesium Lead Halide $\left(\mathrm{CsPbX}_{3}, \mathrm{X}=\mathrm{Br}\right.$ and I) Perovskite Nanocrystals. Angew. Chem. Int. Ed. 2017, 56, 4160-4164.

(24) Madjet, M. E.; Berdiyorov, G. R.; El-Mellouhi, F.; Alharbi, F. H.; Akimov, A. V.; Kais, S. Cation Effect on Hot Carrier Cooling in Halide Perovskite Materials. J. Phys. Chem. Lett. 2017, 8, 4439-4445.

(25) Maity, P.; Yin, J.; Cheng, B.; He, J.-H.; Bakr, O. M.; Mohammed, O. F. Layer-Dependent Coherent Acoustic Phonons in Two-Dimensional Ruddlesden-Popper Perovskite Crystals. J. Phys. Chem. Lett. 2019, 10, 5259-5264.

(26) Stoumpos, C. C.; Cao, D. H.; Clark, D. J.; Young, J.; Rondinelli, J. M.; Jang, J. I.; Hupp, J. T.; Kanatzidis, M. G. Ruddlesden-Popper Hybrid Lead Iodide Perovskite 2D Homologous Semiconductors. Chem. Mater. 2016, 28, 2852-2867.

(27) Zhang, X. T.; Wang, C. C.; Zhang, Y.; Zhang, X. Y.; Wang, S. X.; Lu, M.; Cui, H. N.; Kershaw, S. V.; Yu, W. W.; Rogach, A. L. Bright Orange Electroluminescence from Lead-Free Two-Dimensional Perovskites. ACS Energy Lett. 2019, 4, 242-248.

(28) Cheng, B.; Li, T.-Y.; Maity, P.; Wei, P.-C.; Nordlund, D.; Ho, K.-T.; Lien, D.-H.; Lin, C.-H.; Liang, R.-Z.; Miao, X.; Ajia, I. A.; Yin, J.; Sokaras, D.; Javey, A.; Roqan, I. S.; Mohammed, O. F.; He, J.-H. Extremely Reduced Dielectric Confinement in Two-Dimensional Hybrid Perovskites with Large Polar Organics. Commun. Phys. 2018, $1,80$.

(29) Trinh, M. T.; Wu, X. X.; Niesner, D.; Zhu, X. Y. Many-Body Interactions in Photo-Excited Lead Iodide Perovskite. J. Mater. Chem. A 2015, 3, 9285-9290.

(30) Mondal, N.; Samanta, A. Complete Ultrafast Charge Carrier Dynamics in Photo-Excited All-Inorganic Perovskite Nanocrystals $\left(\mathrm{CsPbX}_{3}\right)$. Nanoscale 2017, 9, 1878-1885.

(31) Zhang, S. F.; Chen, X. K.; Ren, A. M.; Li, H.; Bredas, J. L. Impact of Organic Spacers on the Carrier Dynamics in 2D Hybrid Lead-Halide Perovskites. ACS Energy Lett. 2019, 4, 17-25.

(32) He, J.; Fang, W.-H.; Long, R.; Prezhdo, O. V. Increased Lattice Stiffness Suppresses Nonradiative Charge Recombination in $\mathrm{MAPbI}_{3}$ Doped with Larger Cations: Time-Domain Ab Initio Analysis. ACS Energy Lett. 2018, 3, 2070-2076.

(33) He, J.; Fang, W.-H.; Long, R.; Prezhdo, O. V. Superoxide/ Peroxide Chemistry Extends Charge Carriers' Lifetime but Undermines Chemical Stability of $\mathrm{CH}_{3} \mathrm{NH}_{3} \mathrm{PbI}_{3}$ Exposed to Oxygen: TimeDomain Ab Initio Analysis. J. Am. Chem. Soc. 2019, 141, 5798-5807.

(34) Wang, Y.; Fang, W.-H.; Long, R.; Prezhdo, O. V. Symmetry Breaking at $\mathrm{MAPbI}_{3}$ Perovskite Grain Boundaries Suppresses Charge Recombination: Time-Domain Ab Initio Analysis. J. Phys. Chem. Lett. 2019, 10, 1617-1623.

(35) Li, W.; Zhou, L. J.; Prezhdo, O. V.; Akimov, A. V. Spin-Orbit Interactions Greatly Accelerate Nonradiative Dynamics in Lead Halide Perovskites. ACS Energy Lett. 2018, 3, 2159-2166.

(36) Straus, D. B.; Hurtado Parra, S.; Iotov, N.; Gebhardt, J.; Rappe, A. M.; Subotnik, J. E.; Kikkawa, J. M.; Kagan, C. R. Direct Observation of Electron-Phonon Coupling and Slow Vibrational Relaxation in Organic-Inorganic Hybrid Perovskites. J. Am. Chem. Soc. 2016, 138, 13798-13801.

(37) Thouin, F.; Valverde-Chavez, D. A.; Quarti, C.; Cortecchia, D.; Bargigia, I.; Beljonne, D.; Petrozza, A.; Silva, C.; Srimath Kandada, A. R. Phonon Coherences Reveal the Polaronic Character of Excitons in Two-Dimensional Lead Halide Perovskites. Nat. Mater. 2019, 18, 349-356.

(38) Hintermayr, V. A.; Polavarapu, L.; Urban, A. S.; Feldmann, J. Accelerated Carrier Relaxation through Reduced Coulomb Screening in Two-Dimensional Halide Perovskite Nanoplatelets. ACS Nano 2018, 12, 10151-10158.

(39) Yang, J. F.; Wen, X. M.; Xia, H. Z.; Sheng, R.; Ma, Q. S.; Kim, J.; Tapping, P.; Harada, T.; Kee, T. W.; Huang, F. Z.; Cheng, Y. B.; Green, M.; Ho-Baillie, A.; Huang, S. J.; Shrestha, S.; Patterson, R.; 
Conibeer, G. Acoustic-Optical Phonon Up-Conversion and HotPhonon Bottleneck in Lead-Halide Perovskites. Nat. Commun. 2017, 8,14120 .

(40) Begum, R.; Parida, M. R.; Abdelhady, A. L.; Murali, B.; Alyami, N. M.; Ahmed, G. H.; Hedhili, M. N.; Bakr, O. M.; Mohammed, O. F. Engineering Interfacial Charge Transfer in $\mathrm{CsPbBr}_{3}$ Perovskite Nanocrystals by Heterovalent Doping. J. Am. Chem. Soc. 2017, 139, 731-737.

(41) Giannozzi, P.; Baroni, S.; Bonini, N.; Calandra, M.; Car, R.; Cavazzoni, C.; Ceresoli, D.; Chiarotti, G. L.; Cococcioni, M.; Dabo, I.; Dal Corso, A.; de Gironcoli, S.; Fabris, S.; Fratesi, G.; Gebauer, R.; Gerstmann, U.; Gougoussis, C.; Kokalj, A.; Lazzeri, M.; MartinSamos, L.; et al. Quantum Espresso: A Modular and Open-Source Software Project for Quantum Simulations of Materials. J. Phys.: Condens. Matter 2009, 21, 395502.

(42) Giannozzi, P.; Andreussi, O.; Brumme, T.; Bunau, O.; Buongiorno Nardelli, M.; Calandra, M.; Car, R.; Cavazzoni, C.; Ceresoli, D.; Cococcioni, M.; Colonna, N.; Carnimeo, I.; Dal Corso, A.; de Gironcoli, S.; Delugas, P.; DiStasio, R. A.; Ferretti, A.; Floris, A.; Fratesi, G.; Fugallo, G.; et al. Advanced Capabilities for Materials Modelling with Quantum Espresso. J. Phys.: Condens. Matter 2017, 29, 465901.

(43) Quarti, C.; Grancini, G.; Mosconi, E.; Bruno, P.; Ball, J. M.; Lee, M. M.; Snaith, H. J.; Petrozza, A.; De Angelis, F. The Raman Spectrum of the $\mathrm{CH}_{3} \mathrm{NH}_{3} \mathrm{PbI}_{3}$ Hybrid Perovskite: Interplay of Theory and Experiment. J. Phys. Chem. Lett. 2014, 5, 279-284.

(44) Marini, A.; Hogan, C.; Gruning, M.; Varsano, D. Yambo: An Ab Initio Tool for Excited State Calculations. Comput. Phys. Commun. 2009, 180, 1392-1403.

(45) Umari, P.; Mosconi, E.; De Angelis, F. Infrared Dielectric Screening Determines the Low Exciton Binding Energy of MetalHalide Perovskites. J. Phys. Chem. Lett. 2018, 9, 620-627.

(46) Akimov, A. V.; Prezhdo, O. V. The Pyxaid Program for NonAdiabatic Molecular Dynamics in Condensed Matter Systems. J. Chem. Theory Comput. 2013, 9, 4959-4972.

(47) Akimov, A. V.; Prezhdo, O. V. Advanced Capabilities of the Pyxaid Program: Integration Schemes, Decoherenc:E Effects, Multiexcitonic States, and Field-Matter Interaction. J. Chem. Theory Comput. 2014, 10, 789-804.

(48) Pyxaid2 Package, Quantum-Dynamics-Hub; https://Github. Com/Quantum-Dynamics-Hub/Pyxaid2 (accessed February 1, 2019).

(49) Tully, J. C. Molecular-Dynamics with Electronic-Transitions. J. Chem. Phys. 1990, 93, 1061-1071.

(50) Liu, J.; Prezhdo, O. V. Chlorine Doping Reduces Electron-Hole Recombination in Lead Iodide Perovskites: Time-Domain Ab Initio Analysis. J. Phys. Chem. Lett. 2015, 6, 4463-4469.

(51) Long, R.; Liu, J.; Prezhdo, O. V. Unravelling the Effects of Grain Boundary and Chemical Doping on Electron-Hole Recombination in $\mathrm{CH}_{3} \mathrm{NH}_{3} \mathrm{PbI}_{3}$ Perovskite by Time-Domain Atomistic Simulation. J. Am. Chem. Soc. 2016, 138, 3884-3890.

(52) Long, R.; Fang, W. H.; Prezhdo, O. V. Moderate Humidity Delays Electron-Hole Recombination in Hybrid Organic-Inorganic Perovskites: Time-Domain $A b$ Initio Simulations Rationalize Experiments. J. Phys. Chem. Lett. 2016, 7, 3215-3222. 